\title{
Effect of nanoparticles on dielectric, mechanical and thermal characteristics of $\mathrm{XLPE}_{\mathrm{TiO}}$ nanocomposites
}

\author{
She rif Ess awi ${ }^{1 *}$, Loai Nas rat ${ }^{2}$, Hanafy Ismail ${ }^{1}$ and Jeannette Asaad ${ }^{3}$ \\ Department of Electrical Power and Machines Engineering, Ain Shams University, Cairo, Egypt ${ }^{1}$ \\ Department of Electrical Engineering, Aswan University, Aswan, Egypt ${ }^{2}$ \\ Department of Polymers and Pigments, National Research Centre, Cairo, Egypt ${ }^{3}$
}

Received: 02-July-2021; Revised: 22-September-2021; Accepted: 25-September-2021

(C)2021 Sherif Essawi et al. This is an open access article distributed under the Creative Commons Attribution (CC BY) License, which permits unrestricted use, distribution, and reproduction in any medium, provided the original work is properly cited.

\begin{abstract}
Insulators are required in a power system network to provide ground isolation and mechanical support for line conductors. Different kinds of insulators are being utilized in transmission lines and substations. Many power utilities are now using non-ceramic insulators like Cross-Linked Polyethylene (XLPE) composite insulators. This research aims to develop XLPE nanocomposites for use as power cable insulation in industrial applications. To attain this, XLPE nanocomposites were made with five different loadings of Titanium Dioxide ( $\left.\mathrm{TiO}_{2}\right)$ nanoparticles: $0,1,3,5$ and 7 weight (wt)\% in the presence of a Dicymul Peroxide agent, which is used to minimize nanoparticle agglomeration and enhance compatibility within the polymer matrix. A Scanning Electron Microscope (SEM) was utilized to investigate the structure and distribution of nanoparticles inside the XLPE. The dielectric properties of these developed XLPE/TiOn nanocomposites were studied by measuring the AC dielectric strength with a regulated high voltage testing transformer $(50 \mathrm{~Hz})$. The mechanical properties such as tensile strength and elongation at break were also assessed. The thermal properties of nanocomposites were examined using Thermo Gravimetric Analysis (TGA). When TiO $\mathrm{O}_{2}$ nanoparticles are included in the XLPE matrix, the dielectric strength of $\mathrm{XLPE} / \mathrm{TiO}_{2}$ is shown to be higher than pure XLPE. This indicates that XLPE/TiO 2 nanocomposites have higher dielectric characteristics, with a $\mathrm{TiO}_{2}$ filler loading of $5 \mathrm{wt} \%$ being the best. This might be because TiO 2 nanoparticles have a low surface energy, which prevents them from clustering together. Also, the addition of nano TiO 2 improves the mechanical and thermal characteristics of XLPE nanocomposites. XLPE with 5 wt\% nano TiO $\mathrm{O}_{2}$ showed the best improvement in different properties.
\end{abstract}

\section{Keywords}

Nanocomposites, XLPE, Titanium dioxide filler, Dielectric strength, Tensile strength, TGA.

\section{Introduction}

Because of its high flexibility and mechanical strength, superior dielectric characteristics, strong chemical resistance, ease of processing, and low cost, Cross-Linked Polyethylene (XLPE) has been widely used as an insulating material in high-voltage underground cables [1-3]. Composite materials are made up of two or more components with drastically different physical and chemical characteristics. New materials with properties distinct from the individual components are created as a result of the controlled mixing of the components [4]. Nanocomposites are materials that have at least one component with nanometric dimensions [5].

\footnotetext{
*Author for correspondence
}

Traditional composites differ from nanocomposites in three ways: As a result, nanocomposites have unique properties such as homogeneous structure, optical transparency, and increased or unaffected processability [6]. Ceramic nanocomposites, metal nanocomposites, and polymer nanocomposites [7] are the three types of nanocomposites classified by matrix material.

According to Reference [6], polymer nanocomposites are polymers with a small number of nano-sized fillers (less than 10 weight (wt)\%) dispersed homogenously. Due to their superior material performance, composite materials are frequently chosen over traditional materials. Lightweight materials with higher mechanical strength are chosen for a variety of applications in the automotive, aircraft, and maritime industries. The current review focuses on micro and nanocomposites utilized in high voltage applications. 
Although Lewis [8] developed the term "nanometric dielectrics" [8] or "nanodielectrics" [9] in 1994, it was unclear how the anticipated property changes due to nano-sized filler additions would help electrical insulation. Different properties, such as electrical, mechanical, physical, and thermal, have all been studied extensively [8, 10]. In 1988, Guastavino et al. [11] demonstrated that mica-based methods for groundwall insulation of form-wound generators could provide some advantages. Similar studies on nano $\mathrm{SiO}_{2}$ filler when dispersed in polymers that improve the electrical properties of polymer insulation were conducted by Henk et al. [12] in 1999.

Singha and Thomas [13], Nelson and Fothergill [14] studied the effect of nanodielectrics on power and high voltage engineering, which attracted limited attraction from researchers. Many experiments were carried out in order to gain a basic understanding of how nanoparticles interact with a polymer matrix to change the dielectric characteristics.

The purpose of this research is to examine the impact of introducing nano Titanium Dioxide $\left(\mathrm{TiO}_{2}\right)$ into the XLPE matrix. The dielectric properties such as dielectric strength, mechanical and thermal characteristics will be measured.

Many investigations have shown that traditional microfilled materials can decrease the dielectric strength of insulating polymers, which could be related to bulk charge accumulation [15]. Furthermore, the nanofiller materials cause extensive interfacial areas, which are defined as "an interaction zone between the polymer matrix" and the filler. As a result, the particle type, size, surface, and weight of the nanoparticles inside the polymer nanocomposites play a significant role in their fundamental properties [16, 17].

The effect of high temperatures and thermal aging at high temperatures for $24 \mathrm{hrs}$ on the performance of XLPE nanocomposite insulators has been determined and served to decrease the dielectric strength of XLPE composites. By nano $\mathrm{TiO}_{2}$ addition, dielectric, mechanical and thermal properties are enhanced.

\section{Literature review}

Clay, Acrylic (PA40), Silica (silicon dioxide) $\left(\mathrm{SiO}_{2}\right)$, Alumina $\left(\mathrm{Al}_{2} \mathrm{O}_{3}\right), \mathrm{TiO}_{2}$, Calcium Carbonate $\left(\mathrm{CaCO}_{3}\right)$ and other metal oxides like Magnesium Oxide $(\mathrm{MgO})$, Zinc Oxide $(\mathrm{ZnO})$, et cetera) have all been used in the power industry to improve the performance of insulating materials. To attain good electrical,

1244 mechanical, and thermal properties, these fillers are frequently included in electrical insulating polymers.

Previous studies have found that adding $\mathrm{ZnO}, \mathrm{Al}_{2} \mathrm{O}_{3}$, $\mathrm{SiO}_{2}$, and $\mathrm{Al}\left(\mathrm{OH}_{3}\right)$ nanofillers to XLPE base polymer enhanced electrical characteristics slightly at low filler loading [18-21]. Furthermore, because of its unique properties such as high catalysis activity, nontoxic nature, high mechanical stability, and so on, $\mathrm{TiO}_{2}$ nanocomposites were studied in this work [22-26].

Abd Rahman et al. [21] reported the influence of Zirconium Oxide $\left(\mathrm{ZrO}_{2}\right)$ and $\mathrm{SiO}_{2}$ nanocomposites on the AC breakdown strength of XLPE. Extrusion and crosslinking methods are used to produce pure XLPE and XLPE composites with $(1,3,5$, and $10 \mathrm{wt} \%)$ nanofillers. The AC breakdown strength of XLPE nanocomposite samples was carried out. The findings demonstrated that when nanofillers were used in small amounts, AC breakdown strength performance improved. Different behaviours were seen when $\mathrm{ZrO}_{2}$ and $\mathrm{SiO}_{2}$ were compared.

Abd Rahman et al. [27] investigated the addition of $\mathrm{TiO}_{2}$ and Barium Titanate $\left(\mathrm{BaTiO}_{3}\right)$ to the dielectric strength and space charge of XLPE. According to American Society for Testing and Materials (ASTM) D-149, the dielectric strength performance has been tested. In order to explore charge formation inside the composite samples, the space charge formation was also measured. The results showed that space charge and dielectric strength were both positive. However, in order to achieve improvement, the optimal amount of nanofillers must be carefully assessed. In a study of $\mathrm{BaTiO}_{3}$ and $\mathrm{TiO}_{2}$, distinct behaviours were seen for both properties. The nanofillers in the XLPE matrix were proved to have an excellent effect on this investigation.

Eldesoky et al. [28] studied high voltage XLPE properties improvement using functionalized $\mathrm{ZnO}$ nanoparticles, to accomplish this, XLPE/ZnO nanocomposites were made with four different loadings of $\mathrm{ZnO}$ nanoparticles: 0.5, 2, 3.5, and $5 \mathrm{wt} \%$, in the presence of a suitable coupling agent that reduced nanoparticle aggregation and improved compatibility inside the polymer matrix. SEM was used to investigate the shape and distribution of nanoparticles within the XLPE polymer. The mechanical properties of the material were also assessed. The thermal characteristics of nanocomposites were examined using Differential Scanning Calorimetry (DSC) and Thermo Gravimetric Analysis (TGA). The loss tangent and the dielectric 
constant of these produced XLPE/ZnO nanocomposites were measured at frequencies ranging from $1 \mathrm{~Hz}$ to $1 \mathrm{MHz}$ to investigate their dielectric characteristics. The AC Breakdown voltage was also measured in the sphere-to-sphere field using a regulated high voltage testing transformer. The addition of $\mathrm{ZnO}$ nanoparticles to the XLPE matrix improved the thermal and mechanical properties of the polymer, and the functionalization nanoparticles resulted in efficient dispersion within the polymer matrix, according to the findings.

\section{Methods}

The study paper's testing mechanism is displayed in Figure 1.

The testing mechanismemployed in this investigation is depicted in Figure 1. To begin, different nanofiller concentrations were used to prepare the XLPE/TiO nanocomposite samples. Second, various tests such as dielectric strength, tensile strength, elongation at break, and TGA will be conducted in order to determine the optimal concentration of nano $\mathrm{TiO}_{2}$ filler for improving electrical, mechanical, and thermal properties.

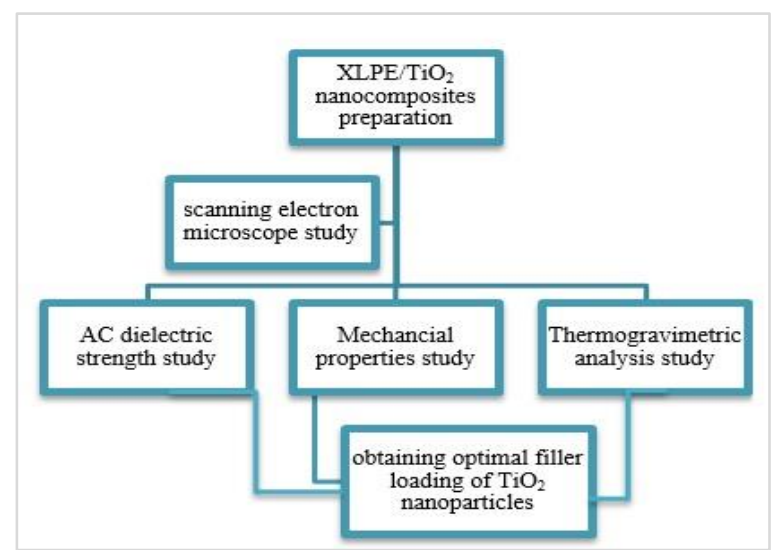

Figure 1 Testing mechanism of research paper

\subsection{Materials}

SABIC KSA provided pure cross-linked low density polyethylene pellets with a density of $0.924 \mathrm{~g} / \mathrm{cm}^{3}$ and a melt flow rate of $2.00 \mathrm{~g} / 10 \mathrm{~min}$ at $2.16 \mathrm{~kg}$ at $190^{\circ} \mathrm{C}$ and a melt flow rate of $2.00 \mathrm{~g} / 10 \mathrm{~min}$ at $2.16 \mathrm{~kg}$ at $190^{\circ} \mathrm{C}$. To make compounding easier, it was crushed into smaller particles with a diameter of less than 0.2 mm. Nano size $\mathrm{TiO}_{2}$ for industrial applications was purchased from Nanotech Egypt.

\subsection{Preparation of XLPE composite samples}

According to ASTM F876- 10e1, LDPE was mixed with dicumyl peroxide ( $3 \mathrm{wt} \%$ ) as a cross linking agent 1245 without any filler to make XLPE. The nanocomposites that were made are XLPE loaded with nano fillers at various percentages $(1,3,5$, and 7$) \mathrm{wt} \%$. Table 1 lists all of the formulations of $\mathrm{XLPE} / \mathrm{TiO}_{2}$ nanocomposites. All nanocomposites were combined in a Barbender Plasticoder type electrically heated chamber (C.W. Pra instrument, INC.50 Hackensack, 230 Volt, 40 Amp). Mixing was performed at $160^{\circ} \mathrm{C}$ and $100 \mathrm{RPM}$ for 10 $\mathrm{min}$ to allow the torque to approach equilibrium. After the mixing was finished, it was pressed at $4 \mathrm{MPa}$ and molded at the same temperature as before. According to ASTM, the sample was cut and prepared with dimensions that best matched each testing technique. Finally, $20 \times 20 \mathrm{~cm}$ square sheets with a thickness of around $1 \mathrm{~mm}$ are produced. Figure 2 shows the different types of nanocomposite samples for XLPE nanocomposites.

Many sheets different composites and bearing varying loads, were purchased in order to carry out the specified testing on them.

Table 1 Mixing formulations of XLPE/TiO2 nanocomposite samples

\begin{tabular}{llll}
\hline Sample & \multirow{2}{*}{ Acronym } & \multicolumn{1}{l}{ XLPE } & Nano TiO \\
\cline { 3 - 4 } & & (wt \%) & (wt \%) \\
\hline$X L P E$ & $\mathrm{~B}$ & 100 & 0 \\
$\mathrm{XLPE}+1 \% \mathrm{TiO}_{2}$ & $\mathrm{~T} 1$ & 99 & 1 \\
$\mathrm{XLPE}+3 \% \mathrm{TiO}_{2}$ & $\mathrm{~T} 3$ & 97 & 3 \\
$\mathrm{XLPE}+5 \% \mathrm{TiO}_{2}$ & $\mathrm{~T} 5$ & 95 & 5 \\
$\mathrm{XLPE}+7 \% \mathrm{TiO}_{2}$ & $\mathrm{~T} 7$ & 93 & 7 \\
\hline
\end{tabular}

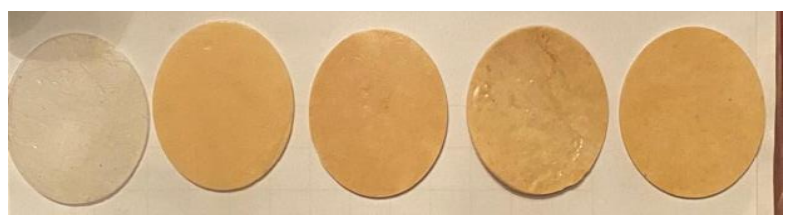

(a)

(b)

(c)

(d)

(e)

Figure 2 Different types of nanocomposite samples for XLPE (a) sample B (b) sample T1, (c) sample T3, (d) sample T5 and (e) sample T7

\subsection{Scanning electron microscope}

Scanning Electron Microscopy (SEM) was utilized to investigate the surface morphology of $\mathrm{XLPE} / \mathrm{TiO}_{2}$ nanocomposites. The micrographs were gathered at an accelerating voltage of $10-15 \mathrm{kV}$, and the microscope was connected to the energy dispersive $\mathrm{X}$-ray analysis unit.

\subsection{Dielectric properties}

The dielectric properties are characterized by the AC dielectric strength. A test cell electrified by a test transformer $(220 \mathrm{~V} / 100 \mathrm{kV})$ was used to determine the 
breakdown strength. The ASTM (D149-09) standard is followed when filling the test cell with transformer oil. All of the samples' breakdown strength has been determined. The dielectric strength test has been studied in two different cases as summarized in Table 2:

i. The first case required placing the nanocomposite samples at two different temperatures. The first testing temperature is set at $30^{\circ} \mathrm{C}$ in order to simulate operating conditions at room temperature. The second testing temperature is set at $250^{\circ} \mathrm{C}$ which can simulate the highest short circuit working condition for a cable operating above 30 $\mathrm{kV}$. By exposing the nanocomposite samples to this temperature in the laboratory oven, the temperature of the nanocomposite samples reached $250^{\circ} \mathrm{C}$. Furthermore, the samples were immersed in oil to limit the possibility of any flashover. The nanocomposite samples should be clean and dry for those two testing conditions before beginning the high voltage test. The voltage was steadily raised at a rate of $2 \mathrm{kV} / \mathrm{s}$ till the breakdown voltage occurred.

ii. The second case required exposing the nanocomposite samples to thermal aging for $24 \mathrm{hrs}$ in different high temperatures $\left(120^{\circ} \mathrm{C}\right.$ and $\left.160^{\circ} \mathrm{C}\right)$.

Table 2 Testing conditions for AC dielectric strength test

\begin{tabular}{ll}
\hline $\begin{array}{l}\text { Different conditions for dielectric } \\
\text { strength test }\end{array}$ & Discerption \\
\hline Condition 1 & $30^{\circ} \mathrm{C} \mathrm{(at} \mathrm{room}$ \\
& temperature) \\
& $250^{\circ} \mathrm{C}$ (to simulate \\
high short circuit) & Thermal aging at \\
& $120^{\circ} \mathrm{C}$ for $24 \mathrm{hrs}$ \\
Condition 2 & Thermal aging at \\
& $160^{\circ} \mathrm{C}$ for $24 \mathrm{hrs}$ \\
\hline
\end{tabular}

\subsection{Mechanical properties}

Mechanical tests such as tensile strength and elongation at break were carried out to show the ability of nanocomposite samples to withstand mechanical forces. The samples should be in the form of a dumbbell with a thickness of $0.2 \mathrm{~cm}$ and a length of 5 $\mathrm{cm}$. The test was performed using the Zwick Roell LTM electrodynamic testing machine in accordance with ASTM D-412.

\subsection{Thermo gravimetric analysis (TGA)}

STA 6000 Perkin Elmer Analyzer and thermogravimetric analysis (TGA, Shimadzu DTG60 , Japan) were used to investigate the thermal stability of $\mathrm{XLPE} / \mathrm{TiO}_{2}$ nanocomposites from $30^{\circ} \mathrm{C}$ to $600^{\circ} \mathrm{C}$ at a heating rate of $10^{\circ} \mathrm{C} / \mathrm{min}$.

\section{Results}

\subsection{Morphological analysis}

Electron microscopy is an effective method for determining the morphology of $\mathrm{TiO}_{2}$ nanoparticles that have been generated. Using a Scanning Electron Microscope (SEM), the structure of the pure XLPE and the dispersion of $\mathrm{TiO}_{2}$ nanoparticles into the polymer matrix were investigated. Figures $3 a, 3 b, 3 c$, $3 d$ and $3 e$ show SEM images. The surface morphology of the composite was modified by embedding $\mathrm{TiO}_{2}$ onto XLPE (Figures $3 b, 3 c, 3 d$ and $3 e$ ). Within the cross-section area and surface of the sample T5 composite, there is good dispersion without the formation of agglomeration (Figure $3 d$ ). While aggregates of $\mathrm{TiO}_{2}$ emerged as white dots within the surface and cross-section area of the $\mathrm{TiO}_{2} / \mathrm{XLPE}$ composite (Figures $3 c$ and $3 e$ ), the white light region is the XLPE filler, and the dark region is the base material.

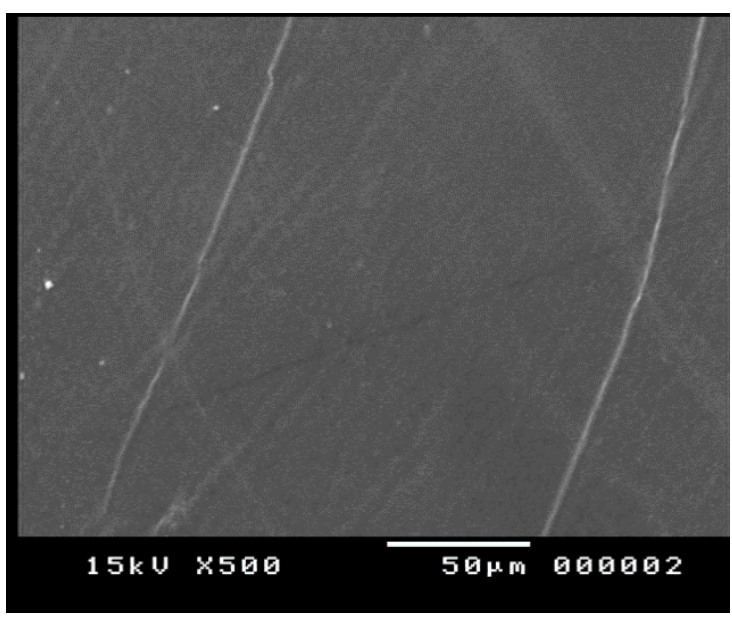

(a)

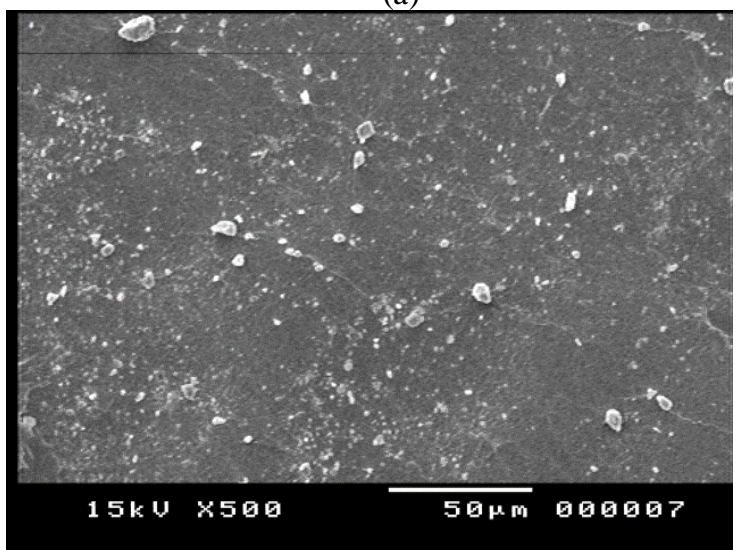

(b) 


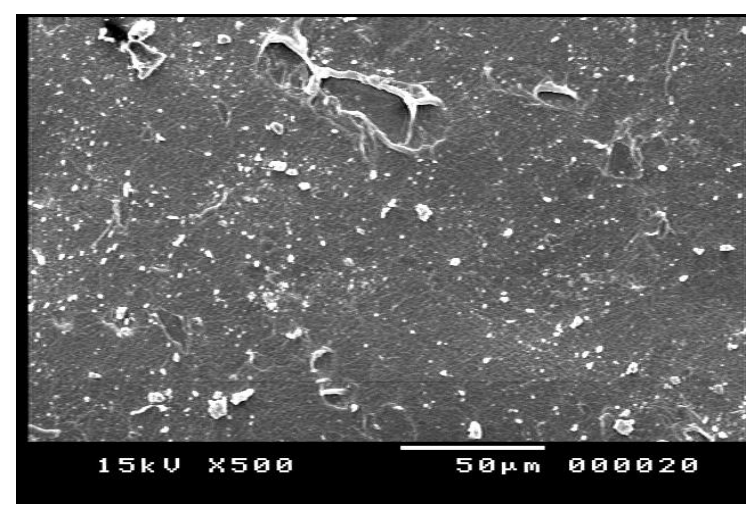

(c)

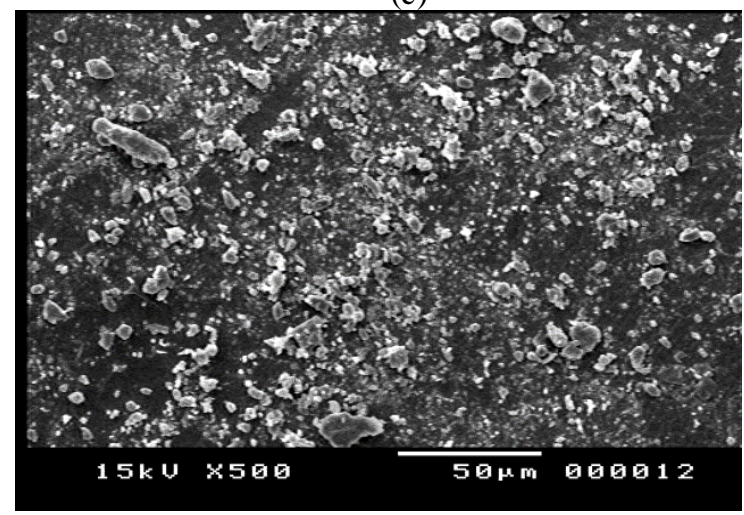

(d)

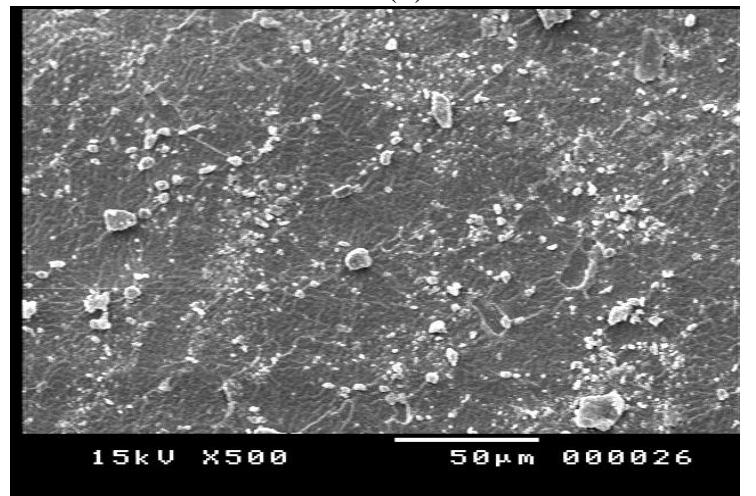

(e)

Figure 3 SEM images of $\mathrm{XLPE} / \mathrm{TiO}_{2}$ nanocomposite samples (a) sample B (b) sample T1, (c) sample T3, (d) sample T5 and (e) sample T7
4.2AC Dielectric strength test results

The ASTM D149-09 standard is used to determine the AC dielectric strength of $\mathrm{XLPE} / \mathrm{TiO}_{2}$ nanocomposites. A test transformer $(50 \mathrm{~Hz}, 220 \mathrm{~V} / 100 \mathrm{kV})$ is connected to the test cell. The measured values of AC dielectric strength are shown in Figure 4. The formation of a strong interfacial area between the polymer matrix and the nanoparticles may be responsible for this. Furthermore, by increasing the concentration of $\mathrm{TiO}_{2}$ nanoparticles, the dielectric strength was increased up to $5 \mathrm{wt} \%$ of $\mathrm{TiO}_{2}$ nano filler, and after that, the dielectric strength decreased.

It can be seen from Figure 4 that a significant rise in the breakdown voltage can only be obtained at low loading percentages. The composite with the highest breakdown voltage has roughly $5 \mathrm{wt} \%$ filler weight. This is followed by a high rate of discrimination with increasing concentration levels.

It can be investigated from Figure 4 that:

- At room temperature $\left(30^{\circ} \mathrm{C}\right)$ condition, the $\mathrm{AC}$ dielectric strength of XLPE loaded with $\mathrm{TiO}_{2}(1,3$, 5 and 7 wt $\%$ ) was improved by $6 \%, 16 \%, 35 \%$ and $24 \%$ to reach $39.98,43.62,50.89$ and $46.64 \mathrm{kV} / \mathrm{mm}$, respectively, compared to pure XLPE $(37.58 \mathrm{kV} / \mathrm{mm})$.

- At high temperature $\left(250^{\circ} \mathrm{C}\right)$ condition, the $\mathrm{AC}$ dielectric strength of XLPE loaded with $\mathrm{TiO}_{2}(1,3$, 5 and $7 \mathrm{wt} \%$ ) was improved by $7 \%, 12 \%, 36 \%$ and $19 \%$ to reach $30.98,32.47,39.29$ and $34.46 \mathrm{kV} / \mathrm{mm}$, respectively, compared to pure XLPE $(28.89 \mathrm{kV} / \mathrm{mm})$.

- When samples are exposed to thermal aging for 24hrs at $120^{\circ} \mathrm{C}$, the AC dielectric strength of XLPE loaded with $\mathrm{TiO}_{2}(1,3,5$ and $7 \mathrm{wt} \%)$ was improved by $7 \%, 9 \%, 23 \%$ and $21 \%$ to reach $24.98,25.47$, 28.76 and $28.26 \mathrm{kV} / \mathrm{mm}$, respectively, compared to pure XLPE $(23.38 \mathrm{kV} / \mathrm{mm})$.

- Finally, when samples are exposed to thermal aging for $24 \mathrm{hrs}$ at $160^{\circ} \mathrm{C}$, the $\mathrm{AC}$ dielectric strength of XLPE loaded with $\mathrm{TiO}_{2}(1,3,5$ and 7 wt $\%)$ was improved by $7 \%, 15 \%, 24 \%$ and $16 \%$ to reach $16.98,18.29,19.68$ and $18.47 \mathrm{kV} / \mathrm{mm}$, respectively, compared to pure XLPE $(15.89 \mathrm{kV} / \mathrm{mm})$. 
Sherif Essawi et al.

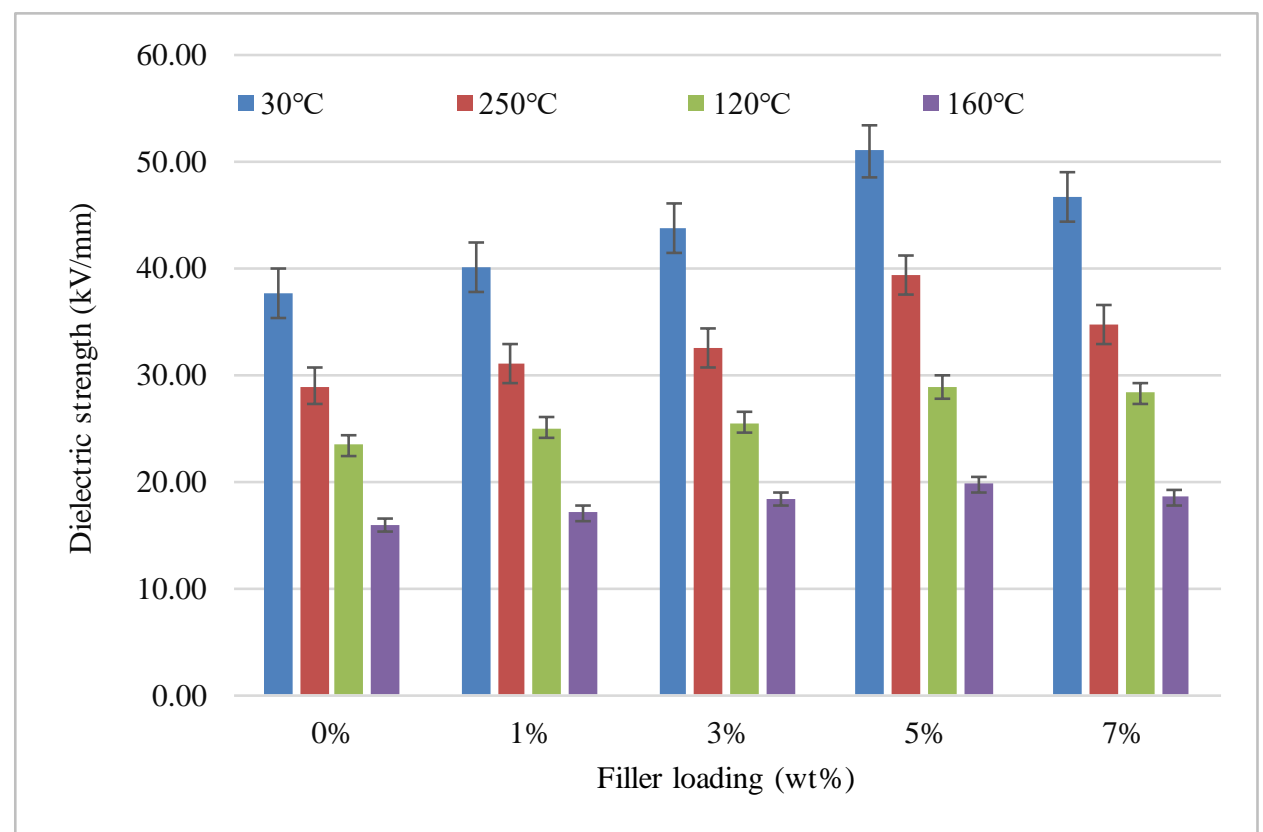

Figure 4 Dielectric strength $(\mathrm{kV} / \mathrm{mm})$ of $\mathrm{XLPE} / \mathrm{TiO}_{2}$ nanocomposite samples at different conditions

4.3Mechanical results

4.3.1 Tensile strength

The dependency of tensile strength on the percentage of nano $\mathrm{TiO} 2$ filler added to XLPE is shown in Figure 5 .

It is shown in Figure 5 that XLPE has an initial value of tensile strength of $8.18 \mathrm{MPa}$. The addition of nano $\mathrm{TiO}_{2}$ with a concentration up to $5 \mathrm{wt} \%$ causes an increase in the tensile strength up to $10.90 \mathrm{MPa}$. The $\mathrm{TiO} 2$ concentration of $7 \mathrm{wt} \%$ causes a decrease in the tensile strength to a value of $9.41 \mathrm{MPa}$.

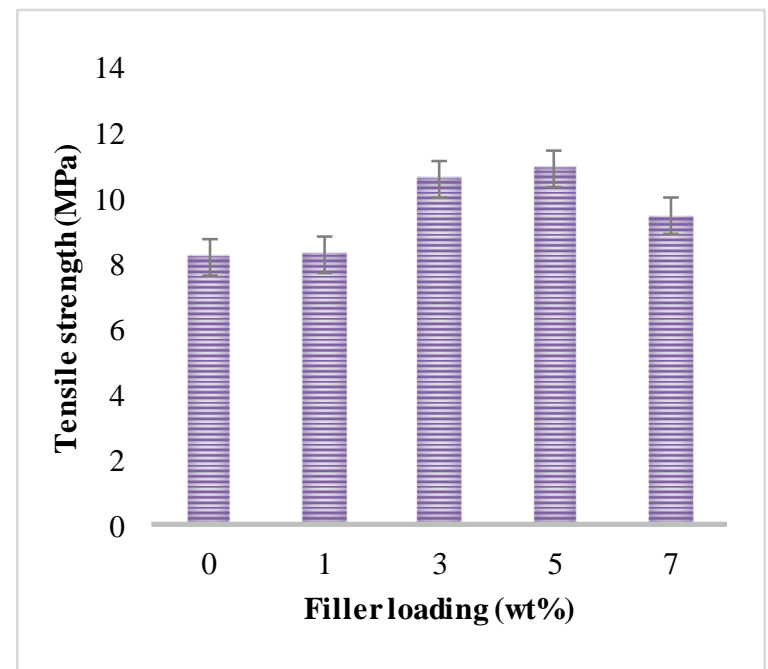

Figure 5 Tensile strength (MPa) for XLPE/TiO2 composite samples

1248

\subsubsection{Elongation at break}

Figure 6 shows the relation between the loaded added $\mathrm{TiO}_{2}$ and elongation at break of XLPE composites. The presence of $\mathrm{TiO}_{2}$ incorporated with XLPE slightly enhanced the tensile strength with optimum strength appeared with $5 \mathrm{wt} \% \mathrm{TiO}_{2}$.

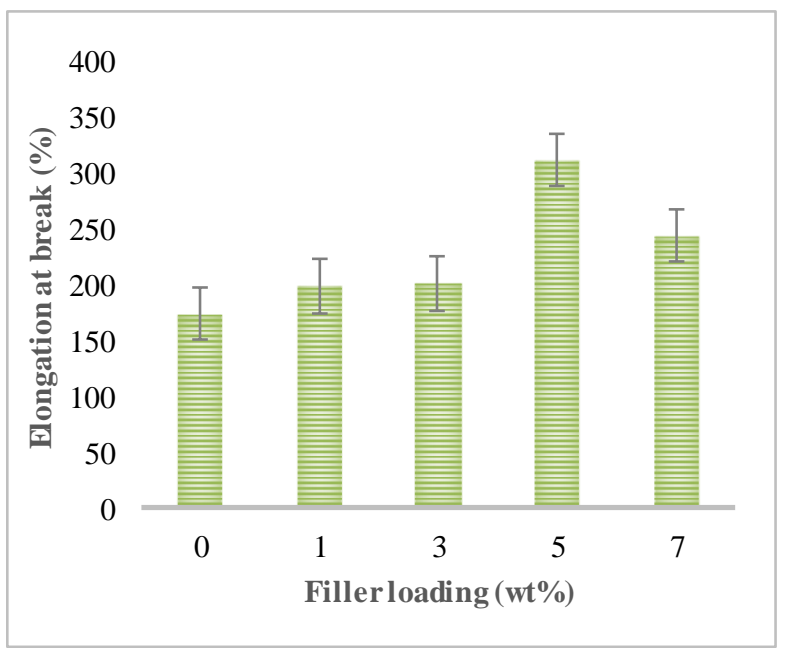

Figure 6 Elongation at break (MPa) for $\mathrm{XLPE}^{\mathrm{T}} \mathrm{TiO}_{2}$ composite samples

Figure 6 shows that the addition of $\mathrm{TiO}_{2}$ nanoparticles increased the elongation at break of XLPE. The high specific surface accessible for interactions with the polymer chains has resulted in this behavior in mechanical characteristics and a rise in the elongation at break value with minimal loading of nanoparticles. 
Also, the addition of nanofiller to most polymer nanocomposites is expected to reduce elongation values, which relates to the restriction of chain mobility caused by the connection between the nanoparticles and the polymer matrix [29].

It can be investigated from Figures 5 and 6 that:

- The addition of nano $\mathrm{TiO}_{2}$ to the XLPE matrix increases the tensile strength and elongation at break up to $5 \mathrm{wt} \%$ and after that, the elongation at break decreases.

- XLPE with added $5 \mathrm{wt} \%$ of nano $\mathrm{TiO}_{2}$ filler has a maximum value of tensile strength (10.89 $\mathrm{MPa})$ and elongation at break (310.91\%) compared to pure XLPE and other nanocomposites concentrations.

\subsection{TGA results}

The rate of degradation in polymer samples with the relevant independent variable is determined by the initial experimental setup and the basic percentage weight loss vs temperature. TGA data as a function of temperature can also be used to track the thermal recovery of mechanical deformation [30]. Thermal degradation could be indicated by irreversible weight loss. The thermal stability of nanocomposites was determined in this study using weight loss at $300^{\circ} \mathrm{C}$, $400^{\circ} \mathrm{C}$, and $480^{\circ} \mathrm{C}$ (decomposition temperatures), as shown in Figure 7 . The thermal stability of $\mathrm{XLPE} / \mathrm{TiO}_{2}$ nanocomposites was determined by the higher values of decomposition temperatures [31]. Weight loss was reduced when $\mathrm{TiO}_{2}$ nanoparticles were added. This indicates that $\mathrm{TiO}_{2}$ nanoparticles added to the XLPE polymer increased thermal stability. This could be owing to the inorganic nanomaterial's high thermal resistance, with an onset temperature of $560^{\circ} \mathrm{C}$ [32-35], or to the matrix chains' decreased mobility as a result of the good bond between the nanoparticles of $\mathrm{TiO}_{2}$ and the XLPE polymer.

It can be also noted from Figure 7 that:

- The weight loss was increased by the temperature rise for all nanocomposites.

- The weight loss is inversely proportional to the loading concentration of nano $\mathrm{TiO}_{2}$.

- The thermal stability of XLPE filled with nano $\mathrm{TiO}_{2}$ (5 wt $\%)$ is better than pure XLPE and other nanocomposites concentrations.

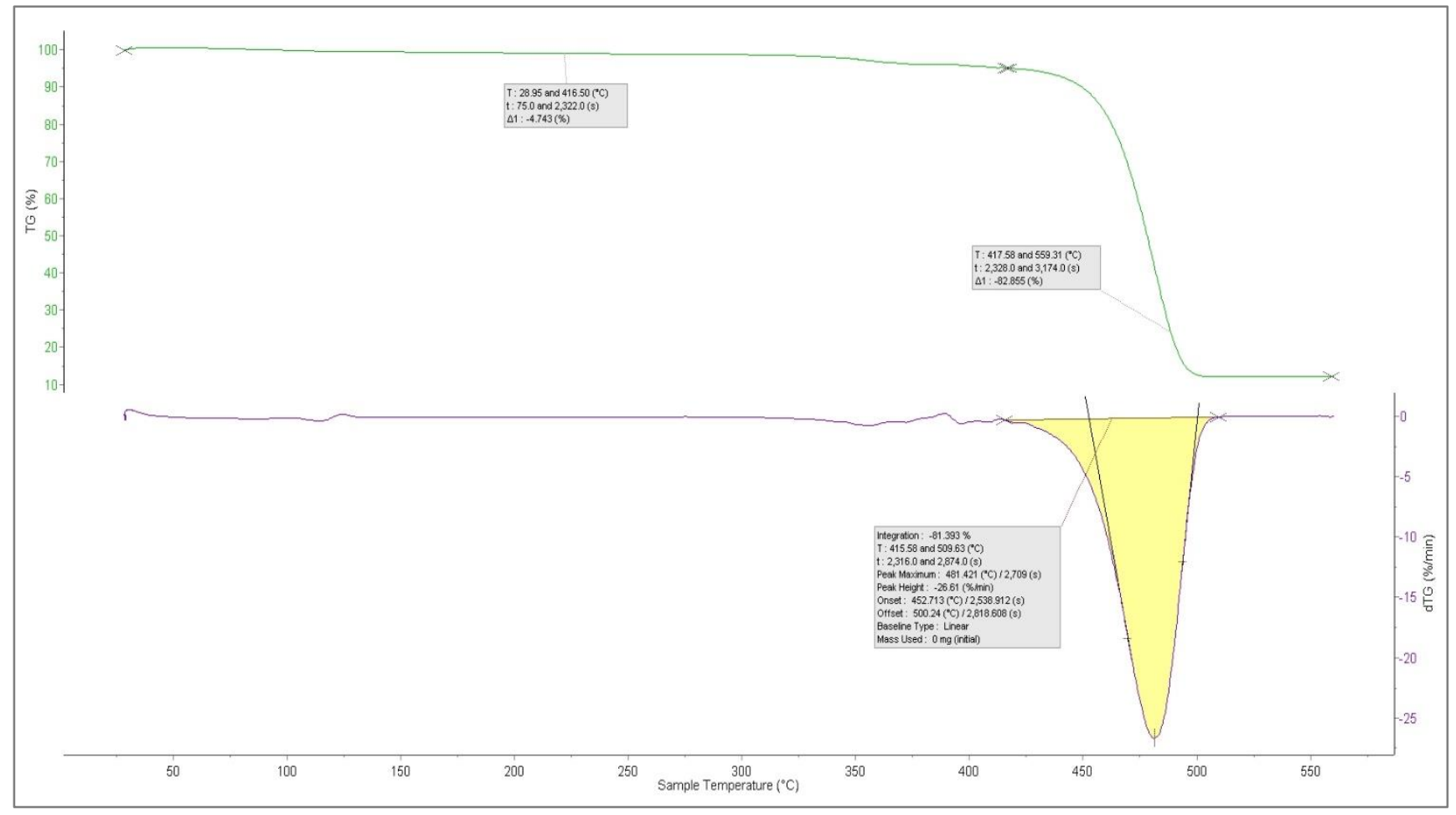

(a) 
Sherif Essawi et al.

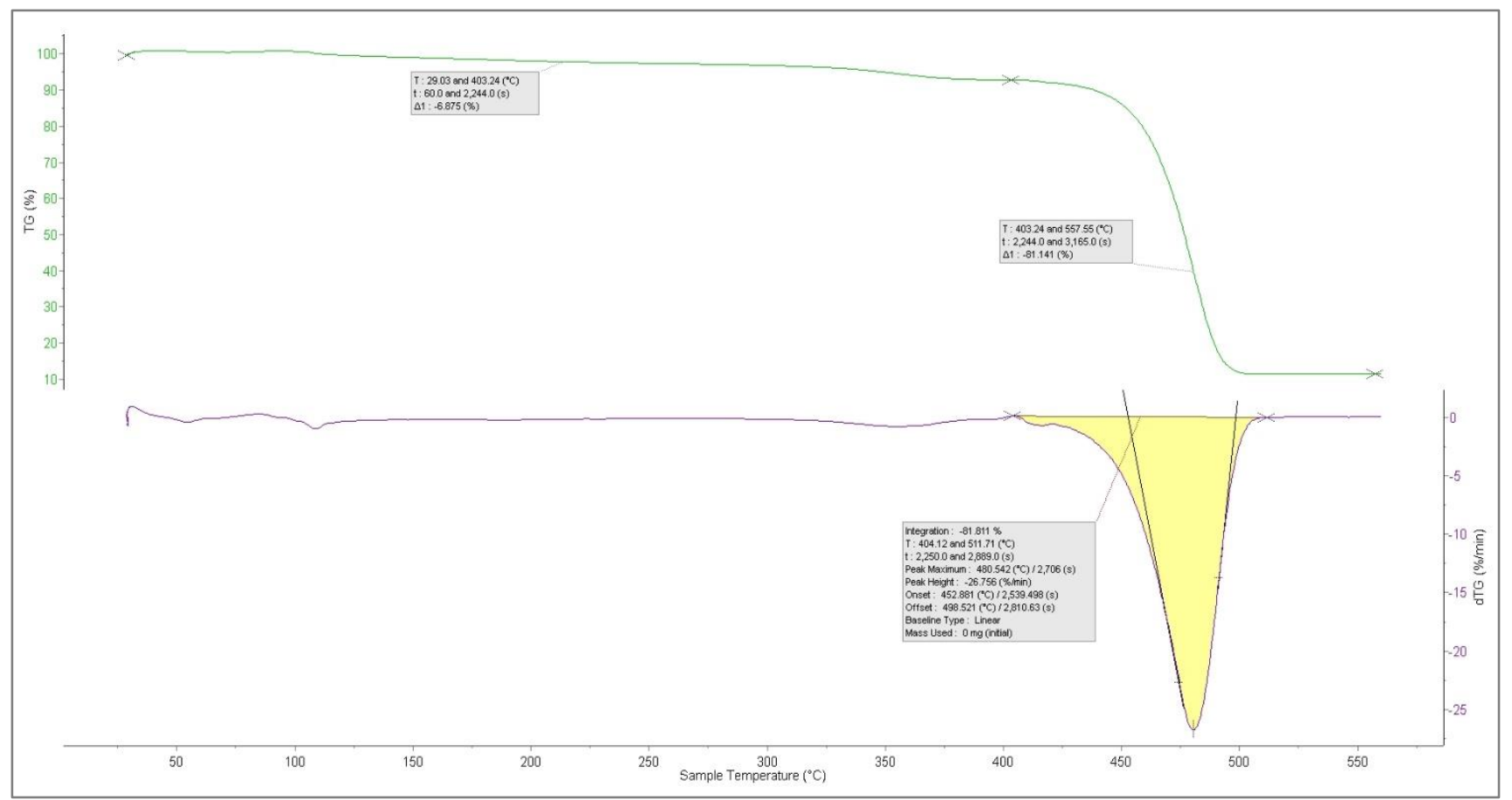

(b)

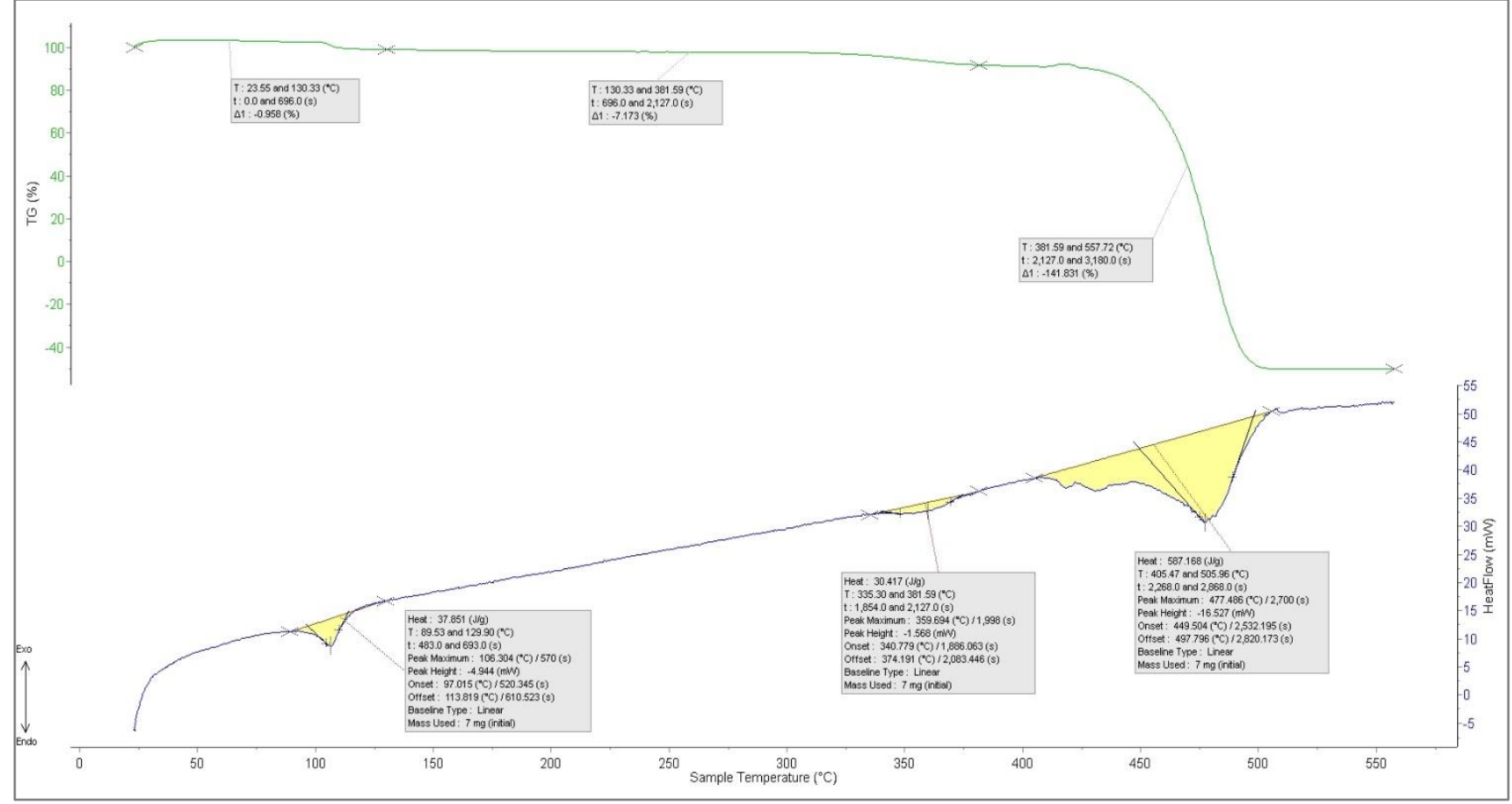

(c) 
International Journal of Advanced Technology and Engineering Exploration, Vol 8(83)

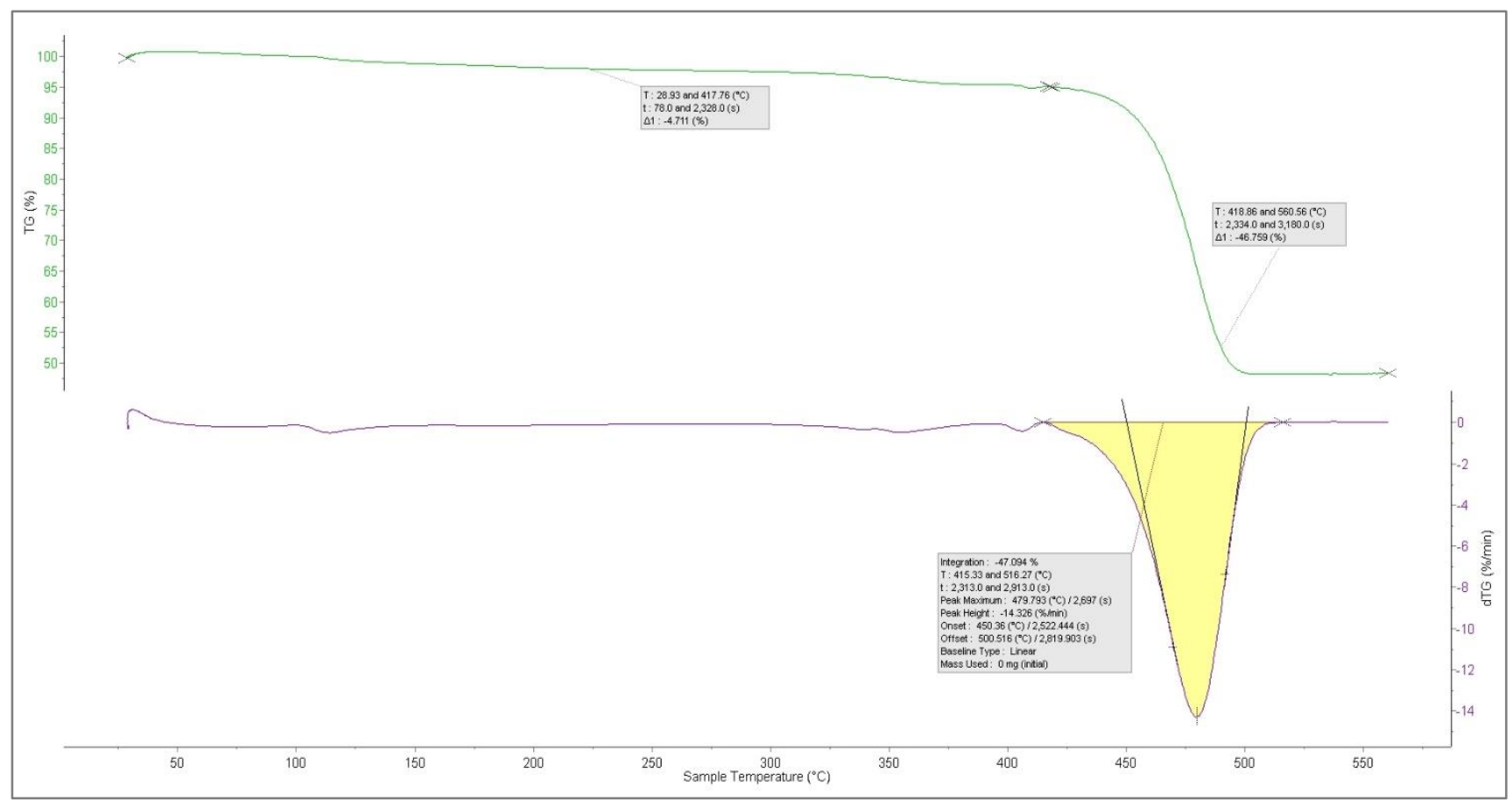

(d)

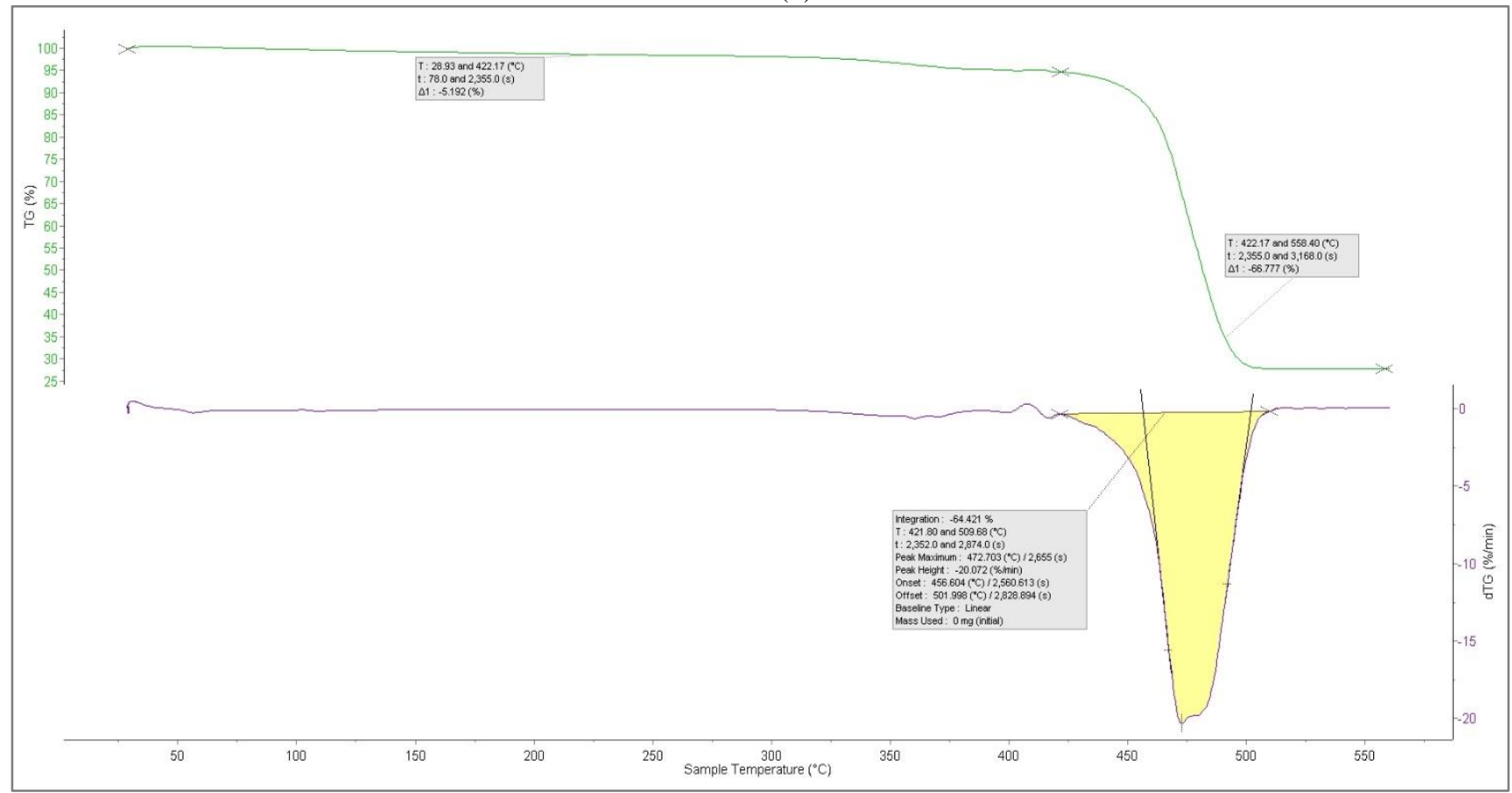

(e)

Figure 7 TGA of (a) sample B (b) sample T1, (c) sample T3, (d) sample T5 and (e) s ample T7

\section{Discussion}

In general, doping a polymer with an inorganic filler creates traps that can capture charge carriers. $\mathrm{TiO}_{2}$ nanoparticles have a uniform distribution in the matrix at low filler loadings, and the density of the emerging traps is sufficient to marginally suppress charge mobility and increase breakdown voltage [36].

To get surface-modified nano $\mathrm{TiO}_{2}$, dicumyl peroxide was used as the coupling agent in this study. On one 
end, the coupling agent is chemically connected to nanoparticles, and on the other, the coupling agent is an alkyl chain that is compatible with the XLPE matrix. The dielectric strength of all polymers reduces with increasing temperature in a clear tendency. The reas on for this is that when the temperature rises, the secondary breakdown processes become more es sential [20].

The increase in mechanical properties of composites in the concentration range of $1-5 \mathrm{wt} \%$ can be attributed to the ease of homogeneously dispersed nano $\mathrm{TiO}_{2}$ in the polymer matrix. Thus, there is an increase in mechanical properties for composites compared with pure XLPE. However, the decrease in composite mechanical properties with further addition of $\mathrm{TiO}_{2}$ over $5 \mathrm{wt} \%$ may be explained by the agglomeration of nano $\mathrm{TiO}_{2}$. The agglomeration of nano $\mathrm{TiO}_{2}$ is strictly associated with inhomogeneous distribution of nano $\mathrm{TiO}_{2}$ in the matrix and reduced interaction between nano $\mathrm{TiO}_{2}$ and the XLPE matrix. Another possibility is due to the high viscosity of the mixture at high concentrations of nano $\mathrm{TiO}_{2}$, which causes an improper mixing process. TGA test illustrates that XLPE with $5 \mathrm{wt} \% \mathrm{TiO} 2$ nano filler represents the best sample from stability point and pure XLPE represents the worst sample as shown in Figure 7. It indicates that nano $\mathrm{TiO}_{2}$ filler plays an important role in the thermal stability improvement. A complete list of abbreviations is shown in Appendix I.

\section{Conclusion and future work}

The primary insulation in power cables is cross-linked polyethylene. Their electrical, physical, and chemical properties are all significant. This paper is interested in improving these characteristics, particularly its electrical characteristics, by adding $\mathrm{TiO}_{2}$ nanoparticles, which are limited in terms of publication issues because most researchers are focused on high-and low-density polyethylene. In this research, industrial-scale $\mathrm{XLPE} / \mathrm{TiO}_{2}$ nanocomposites with various titanium dioxide nanoparticle loading ratios were manufactured. The thermal, mechanical, and dielectric characteristics represented in the dielectric strength of the nanocomposites were measured. The dispersion of nano $\mathrm{TiO}_{2}$ filler into the XLPE matrix improved the electrical, mechanical, and thermal properties of the polymers, according to the results. The dielectric strength of $\mathrm{TiO}_{2}$ nanocomposites was higher than that of XLPE. The inter particle distance reduces as the percentage weight of nanoparticles increases, causing a barrier to charge carriers transferring and forming a strong bond, resulting in higher dielectric strength. So, it was shown that increasing the amount of $\mathrm{TiO}_{2}$ nanoparticles reduced the dielectric strength, which could be because the high concentration of nanoparticles causes greater agglomeration, resulting in a significant reduction in dielectric strength.

However, there are many aspects which may affect the performance of XLPE and further research is suggested to improve the performance of XLPE.

- Studying insulation systems from the point of aging for XLPE composites on the practical site.

- It is suggested to combine two or three nanofillers with XLPE and study their electrical, mechanical, physical and thermal properties.

- Computer software can be used to calculate the average leakage current, aging time, etc. by using a data acquisition system.

\section{Acknowledgment}

None.

Conflicts of interest

The authors have no conflicts of interest to declare.

\section{References}

[1] Huang X, Ma Z, Jiang P, Kim C, Liu F, Wang G, et al. Influence of silica nanoparticle surface treatments on the water treeing characteristics of low density polyethylene. In 9th international conference on the properties and applications of dielectric materials 2009 (pp. 757-60). IEEE.

[2] Li X, Liu X, Xu M, Xie D, Cao X, Wang X, et al. Influence of compatibilizers on the water-tree property of montmorillonite/cross-linked polyethylene nanocomposites. In international conference on the properties and applications of dielectric materials 2012 (pp. 1-4). IEEE.

[3] Li X, Xu M, Xin L, Xie D, Cao X. Study of montmorillonite on morphology and water treeing behavior in crosslinking poly ethylene. In proceedings of international symposium on electrical insulating materials 2011(pp. 205-8). IEEE.

[4] Matthews FL, Rawlings RD. Composite materials: engineering and science. Elsevier; 1999.

[5] https://en.wikipedia.org/wiki/Nanocomposite. Accessed 9 December 2015.

[6] Tanaka T, Montanari GC, Mulhaupt R. Polymer nanocomposites as dielectrics and electrical insulationperspectives for processing technologies, material characterization and future applications. IEEE Transactions on Dielectrics and Electrical Insulation. 2004; 11(5):763-84.

[7] Camargo PH, Satyanarayana KG, Wypych F. Nanocomposites: synthesis, structure, properties and 
new application opportunities. Materials Research. 2009; 12(1):1-39.

[8] Lewis TJ. Nanometric dielectrics. IEEE Transactions on Dielectrics and Electrical Insulation. 1994; 1(5):812-25.

[9] Frechette MF, Trudeau ML, Alamdar HD, Boily S. Introductory remarks on nanodielectrics. IEEE Transactions on Dielectrics and Electrical Insulation. 2004; 11(5):808-18.

[10] Cao Y, Irwin PC, Younsi K. The future of nanodielectrics in the electrical power industry. IEEE Transactions on Dielectrics and Electrical Insulation. 2004; 11(5):797-807.

[11] Guastavino F, Briano L, Gallesi F, Torello E. Corona resistant insulating systems characterization for low voltage rotating machine. In conference on electrical insulation and dielectric phenomena 2019 (pp. 694-7). IEEE.

[12] Henk PO, Kortsen TW, Kvarts T. Increasing the electrical discharge endurance of acid anhydride cured DGEBA epoxy resin by dispersion of nanoparticle silica. High Performance Polymers. 1999; 11(3):28196.

[13] Singha S, Thomas MJ. Dielectric properties of epoxy nanocomposites. IEEE Transactions on Dielectrics and Electrical Insulation. 2008; 15(1):12-23.

[14] Nelson JK, Fothergill JC. Internal charge behaviour of nanocomp osites. Nanotechnology. 2004; 15(5).

[15] Nelson JK, Fothergill JC, Dissado LA, Peasgood W. Towards an understanding of nanometric dielectrics. In annual report conference on electrical insulation and dielectric phenomena 2002 (pp. 295-8). IEEE.

[16] Bréchet Y, Cavaillé JY, Chabert E, Chazeau L, Dendievel R, Flandin L, et al. Polymer based nanocomposites: effect of filler-filler and filler-matrix interactions. Advanced Engineering Materials. 2001; 3(8):571-7.

[17] Šupová M, Martynková GS, Barabaszová K. Effect of nanofillers dispersion in polymer matrices: a review. Science of Advanced Materials. 2011; 3(1):1-25.

[18] Mansor NS, Nazar NS, Fairus M, Ishak D, Mariatti M, Halim HS, et al. Electrical treeing characteristics of XLPE material containing treated $\mathrm{ZnO}$ nano-filler. In international conference on robotics, vision, signal processing and power applications 2019 (pp. 305-11). Springer, Singap ore.

[19] Daskalopoulos K, Verginadis D, Yin Y, Danikas MG, Sarathi R. Surface discharges and flashover voltages: investigation of XLPE samples with $\mathrm{SiO}_{2}$ and $\mathrm{Al}_{2} \mathrm{O}_{3}$ nanoparticles. In international sy mposium on electrical insulating materials (ISEIM) 2020 (pp. 237-40). IEEE.

[20] Wang S, Yu S, Xiang J, Li J, Li S. DC breakdown strength of crosslinked polyethylene based nanocomposites at different temperatures. IEEE Transactions on Dielectrics and Electrical Insulation. 2020; 27(2):482-8.

[21] Abd RAB, Abd RMS, Ariffin AM, Ali NN, Abd GAB, Lau KY, et al. Influence of $\mathrm{SiO}_{2}$ and $\mathrm{ZrO}_{2}$ nanocomposite on the $\mathrm{AC}$ breakdown strength of crosslinked polyethylene (XLPE). In international conference on the properties and applications of dielectric materials (ICPADM) 2021(pp. 378-81). IEEE.

[22] Thabet A, Mubarak YA, Bakry MJ. A review of nanofillers effects on industrial polymers and their characteristics. International Journal of Engineering Science. 2011; 39:377-403.

[23] Kołodziejczak-radzimska A, Jesionowski T. Zinc oxide-from synthesis to application: a review. Materials. 2014; 7(4):2833-81.

[24] Chavali MS, Nikolova MP. Metal oxide nanoparticles and their applications in nanotechnology. SN Applied Sciences. 2019; 1(6):1-30.

[25] Mohan AC, Renjanadevi B. Preparation of zinc oxide nanoparticles and its characterization using scanning electron microscopy (SEM) and X-ray diffraction (XRD). Procedia Technology. 2016; 24:761-6.

[26] Siddiqi KS, Rahman AU, Husen A. Properties of zinc oxide nanoparticles and their activity against microbes. Nanoscale Research Letters. 2018; 13(1):1-3.

[27] Abd RAB, Abd RMS, Ariffin AM, Ali NN, Abd GAB, $\mathrm{Lau} \mathrm{KY}$, et al. Investigation of $\mathrm{BaTiO}_{3}$ and $\mathrm{TiO}_{2}$ based nano-fillers on the space charge and electrical strength of cross-linked polyethylene (XLPE). In international conference on the properties and applications of dielectric materials 2021 (pp. 374-7). IEEE.

[28] Eldesoky E, Said A, Nawar A, Abdallah M, Kamel S. High voltage cross-linked polyethylene insulator characteristics improvement using functionalized $\mathrm{ZnO}$ nanoparticles. Egyptian Journal of Chemistry. 2020; 63(12):4929-39.

[29] Yu Q, Selvadurai AP. Mechanical behaviour of a plasticized PVC subjected to ethanol exposure. Polymer Degradation and Stability. 2005; 89(1):10924.

[30] Juliana NC, Chibuike NA, Josiah E. Evaluation of the thermal stability of poly (O-pheny lenediamine)(PoPD) by thermogravimetric analysis (TGA). American Journal of Nanosciences. 2019; 5:18-22.

[31] El-sayed NS, El-sakhawy M, Hesemann P, Brun N, Kamel S. Rational design of novel water-soluble ampholytic cellulose derivatives. International Journal of Biological Macromolecules. 2018; 114:363-72.

[32] Huang C, Qian X, Yang R. Thermal conductivity of polymers and polymer nanocomposites. Materials Science and Engineering: R: Reports. 2018; 132:1-22.

[33] Khan H, Amin M, Ali M, Iqbal M, Yasin M. Effect of micro/nano-SiO \$_ $\{2\}$ \$ on mechanical, thermal, and electrical properties of silicone rubber, epoxy, and EPDM composites for outdoor electrical insulations. Turkish Journal of Electrical Engineering \& Computer Sciences. 2017; 25(2):1426-35.

[34] Corcione CE, Frigione M. Characterization of nanocomposites by thermal analy sis. Materials. 2012; 5(12):2960-80.

[35] Nabinejad O, Sujan D, Rahman ME, Davies IJ. Determination of filler content for natural filler polymer composite by thermogravimetric analysis. Journal of Thermal Analysis and Calorimetry. 2015; 122(1):227-33. 
[36] Gao JG, Li X, Yang WH, Zhang XH. Space charge characteristics and electrical properties of micro-nano ZnO/LDPE composites. Crystals. 2019; 9(9):1-13.

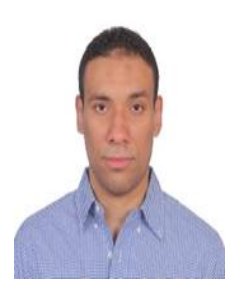

Sherif Essawi was born in Cairo, Egy pt in 1983. He received his B. Sc from Faculty of Engineering, Ain shams University, Electrical Power and Machine department in 2005. He works as a design engineer for Low and Medium voltage Networks. Also, he worked in the planning of the high Voltage network in Egypt. He received his MSc in 2012 from the faculty of Engineering, Ain shams university, Electrical and high voltage department. His researches focus on the improvement of High voltage insulation in cables. Email: Eng.sherifessawi@gmail.com

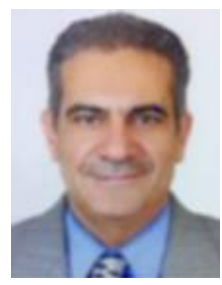

Loai Nasrat is a professor at Aswan University, Faculty of Eng., Elect. P\&M Department. He has been actively involved in both basic and applied research in the area of high voltage engineering. His research interests include high voltage insulators, Nano polymeric materials, high voltage cables insulations, aged oil transformer, and environmental studies. Author and co-author of more than 60 papers on high voltage polymeric insulating materials, Nano insulating materials published in technical journals and proceedings of national and international conferences. Dr. Loai is a member of the Egy ptian Sub-Committee of CIGRE.

Email: Loaisaad@yahoo.com

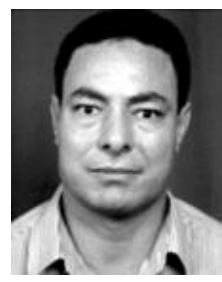

Hanafy Ismail was born in Cairo, Egypt, in 1956. He received the B.S. and M.S. degrees in electrical engineering from Electrical Engineering Department, Faculty of Engineering at Ain-Shams University, Cairo, in 1979 and 1984, respectively. He received the Ph.D. degree in 1989 from Electrical Engineering Department at the University of Windsor, Windsor, ON, Canada., Since graduation, he has been working at the Electrical Engineering Department, Faculty of Engineering, Ain-Shams University. He is now a Professor, on leave of absence from Ain-Shams University, joining the Electrical Engineering Department at the College of Technological Studies in Kuwait since 1997. He deals mainly with the high voltage power transmission and their associated electrostatics and electromagnetic fields. $\mathrm{He}$ is also working in the area of power systems, underground cables, and fault detection on transmission lines.

Email: hanafy_22356@hotmail.com
Jeannette Asaad is a professor at the National Research Center (NRC), polymers and pigments department. She joined the department in 1985. She was born in Egypt and graduated from Ain Shams University in 1981, she also received her M.Sc and Ph.D. in 1995 and 2002 from Cairo University, respectively. She has been appointed at the NRC as Researcher (2002), as Associate Prof. (2008) and Professor (2014). Dr. Jeannette granted a postdoctoral fellowship to Germany through DFG in 2011 at the Institute of Polymer Materials and Plastics Engineering, Clausthal University of Technology. Where, she carried out some work on the influences of proton-donators onto epoxy resins leading to reaction kinetics. She supervised M.sc and Ph.D student to completion. These studies dealt with polymer composites and rubber blends as high voltage insulators and cables. She published more than 40 peer-reviewed papers in national, international journals and conferences. Reviewed papers for international Journals: Polymer Bulletin, Journal of applied polymer science, Polymer engineering and science and Journal of Elastomers and Plastics.

Email: na_jeannette@yahoo.com

Appendix I

\begin{tabular}{lll}
\hline S.N. & Abbre viation & Description \\
\hline 1 & $\mathrm{Al}_{2} \mathrm{O}_{3}$ & Aluminum Oxide \\
\hline 2 & $\mathrm{Al}(\mathrm{OH})_{3}$ & Aluminum Hydroxide \\
\hline 3 & $\mathrm{ASTM}$ & $\begin{array}{l}\text { American Society for Testing and } \\
\text { Materials }\end{array}$ \\
\hline 4 & $\mathrm{BaTiO}_{3}$ & Barium Titanate \\
\hline 5 & $\mathrm{CaCO}_{3}$ & Calcium Carbonate \\
\hline & $\mathrm{DSC}^{\mathrm{MgO}}$ & Differential Scanning Calorimetry \\
\hline 6 & $\mathrm{MgO}$ & Magnesium Oxide \\
\hline 7 & $\mathrm{PA}_{40}$ & Acrylic \\
\hline 8 & $\mathrm{SEM}_{9}$ & Scanning Electron Microscope \\
\hline 10 & $\mathrm{SiO}_{2}$ & Silicon Dioxide \\
\hline 11 & $\mathrm{TiO}_{2}$ & Thermo Gravimetric Analysis \\
\hline 12 & $\mathrm{wt}$ & Titanium Dioxide \\
\hline 13 & $\mathrm{XLPE}^{\mathrm{ZnO}}$ & Weight Percentage \\
\hline 14 & $\mathrm{ZnO}$ & Zross Linked Polyethylene \\
\hline 15 & $\mathrm{ZrO}_{2}$ & Zirconium Oxide \\
\hline
\end{tabular}

